\title{
Research of Oil Product Sorption Processes by Ferromagnetic Sorbents
}

\author{
V. Mironovs ${ }^{1}$, J. Treijs ${ }^{1}$, E. Teirumnieks ${ }^{2}$ \\ ${ }^{1}$ Riga Technical University, Riga, Latvia, \\ ${ }^{2}$ Rezekne Higher Education Institution, Rezekne, Latvia
}

\begin{abstract}
In paper, is given overview of sorbents with ferromagnetic particles. The series of newly designed composite sorbents SOMSOR, are described. Described experiment of oil spill collection from water surface, which comprises of sorbent spreading and collection. Oil sorption by capillary forces, is discussed. Concluded that use of ferromagnetic sorbents a promising direction in the field of water purification from light oil products since it allows expanding the scope of the used powder sorbents, to use the high-mechanized methods of collecting by means of magnetic and electromagnetic devices.
\end{abstract}

Keywords: oil spill collection, ferromagnetic sorbent, metal powder, composite sorbent, buoyancy.

\section{INTRODUCTION}

Possibilities for use of the disperse sorbents for collecting oils and other oil products (OPs) poured on a water surface and at the bottom of a reservoir, have been considered in many papers, including [1-3]. The sorbent which is used for collecting OPs poured in water, has to possess the following properties:

- to possess good sorption to OPs;

- to have low cost;

- to be non-toxic;

- good to be sprayed;

- to be reused;

- good to be grasped by mechanized means;

- easy to surrender OPs at the place of collecting.

High interest in the powder sprayed sorbents with magnetic properties (PSMS) is observed during the recent years. Works are conducted for creation and application of such sorbents at the Riga Technical University and the Rezekne Higher Education Institution in the course of several years [4-8]. Iron powders were generally used as initial materials for their preparation. For increase of efficiency of the processes of sorption and decrease in expenses, topical issues are related to use of the crushed rolling scale, and also to development and application of composite sorbents, et al. In this case also research of processes of sorption, removal of a collected sorbent with oil product (SOP), subsequent technologies of utilization and regeneration is very important.

\section{SOME VARIETIES OF POWDER SORBENTS}

\subsection{Sorbents on the basis of rolling scale}

Rolling scale (RS) of Liepaja metallurgical plant [4] was offered to be used as material for removal of OPs from water. Its advantages in this case: low cost since scale is a little-used technological residue of production; fast grindability to the state suitable for dispersion on a water surface; good magnetic properties and safety for environment.

For researches the rolling scale has been used, which is formed during production of the low-alloyed flint-manganese steel of the brands $35 \mathrm{GS}, 25 \mathrm{G} 2 \mathrm{~S}$, applied for production of construction fittings. Scale in steel-rolling production of the enterprise is collected by means of the crane supplied with an electromagnet and is stored.

Our researches have showed that scale with the minimum period of storage is appropriate to be used for production of a sorbent. It is established that the optimum size PO (the size of particles) has to be within 1-2 $\mathrm{mm}$.

During studies it was also established that efficiency of sorption is increased by preliminary mixing of scale powder with OPs and the subsequent drying of mixture [6].

\subsection{Sorbents based on iron powders}

Powder materials on the basis of powders of iron ASC 100.29 (sprayed, used in production of constructional details to methods of powder metallurgy), MH 80.23 (restored spongy, used in the production of self-greased sliding bearings), 
M20/80-19 (with low content of carbon) and R-12 (with low content of hydrogen, used in production of frictional products) were used as a research material. All the powders are produced by Höganäs $A B$ company (Sweden). Also the powder CMS was used, which represents residue from filters. These materials were tested in a condition of delivery, as well as after processing in oil and subsequent ignition [7].

\subsection{Composite sorbents}

One of the composite sorbents (CS) on the basis of iron was offered earlier in [3]. Its feature is represented by especially small dispersion $(5-10 \mu \mathrm{m})$. Such sorbent doesn't destroy the film of oil product, and modifies its properties. Its buoyancy increases, however fluidity sharply decreases. Due to this its spraying is made difficult. Efficiency of the method has appeared to be rather low since the modification process is slow, the size of lifting effort is small, and the sorbent cost is high.

We have developed the COMSOR type composite sorbents [8]. These represent mixes of iron fine dispersed powders with cenospheres (the waste formed when burning coal (Fig. 1). Use of modification of sorbents has succeeded to increase sorption ability of a sorbent by 2-5 times with its bulk mass of just $0.6-0.8$ (in relation to earlier used dry sorbents on the basis of iron powders having the bulk mass of $1.4-1.8 \mathrm{~g} / \mathrm{cm}^{3}$ ).

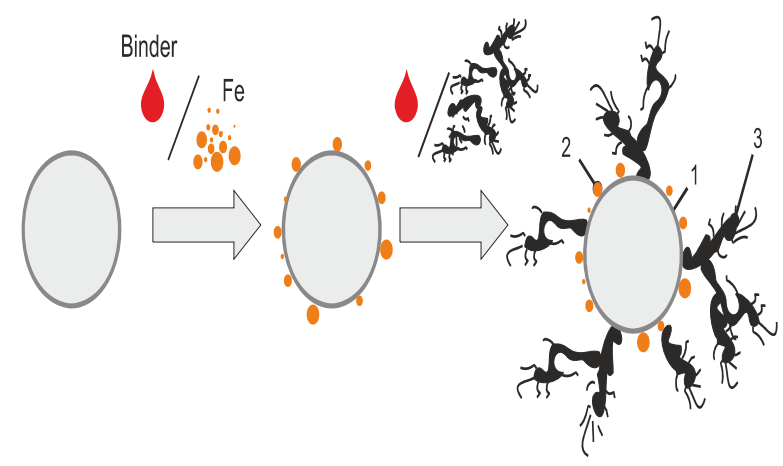

Fig.1. Scheme of creation of COMSOR composite sorbent

Important role for the process of sorption is played by a particle surface and its form (Fig. 2). The best results with regard to efficiency have appeared for the particles of a powder sorbent M20/80-19 (a) having highly branched surface, and at a composite sorbent Comsor M (c), differing for its small bulk weight and increased buoyancy.
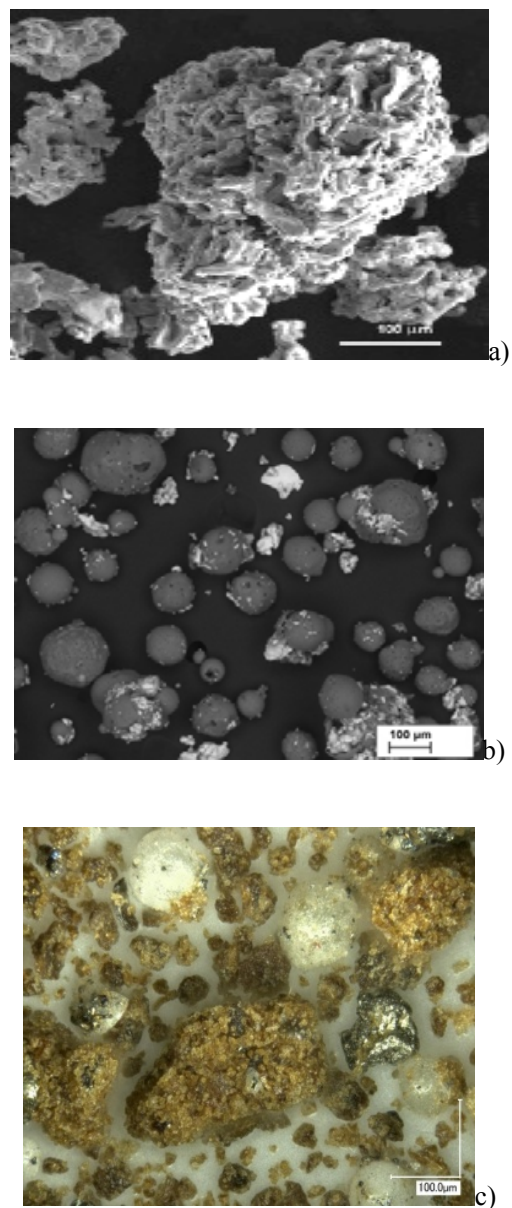

Fig. 2. Morphology of a particle surface of a powder sorbent M20/80-19 (a), composite sorbent Comsor A(b) and sorbent Comsor M (c).

\section{EQUIPMENT. EXPERIMENT METHODOLOGY}

Experimental tests of the operation of sorbents are performed on the experimental installation made at the Rezekne Higher Education Institution (Latvia) (Fig. 3). Installation is equipped with highly effective permanent magnets FeNiB. It allows installation of magnets of various loading capacity and alteration of distance between the polluted water surface, and a magnet.

The experiment methodology has included the following stages: filling in non-magnetic capacity of water at the fixed height (not less than $30 \mathrm{~mm}$ ); application on its surface of oil product (transmission oil TAD-17 with the specific weight of $0,8 \mathrm{~g} / \mathrm{cm} 3$ ); holding during 2-3 minutes for development of stable film, spraying of the set mass of powder on the film by means of a rotating disk [7]; removal of the collected oil product and carrying out further researches for assessment of sorption ability and thermogravimetric research. 


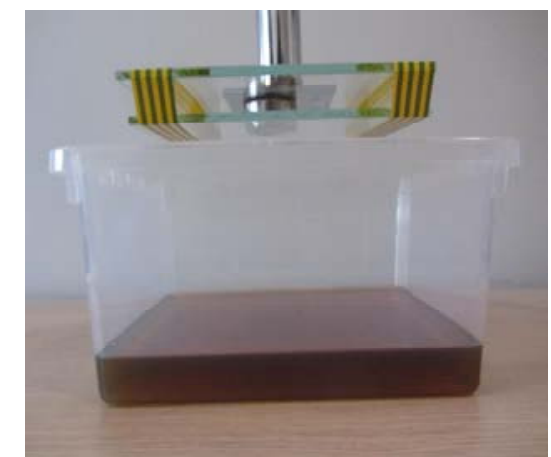

a)

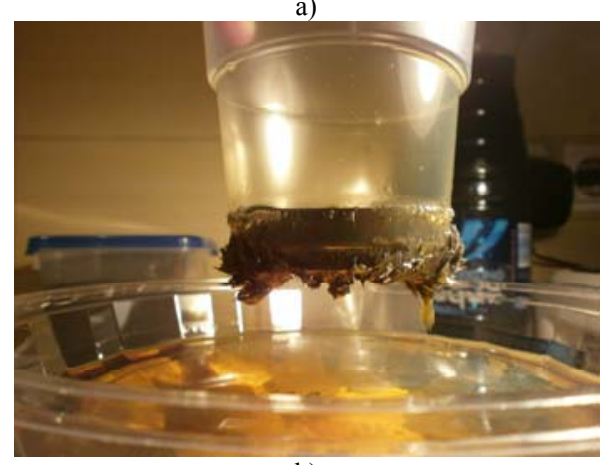

b)

Fig. 3. General view of the experimental equipment(a) and working process of sorption(b).

Previously bulk weight, the form and the size of particles of a sorbent, its fluidity, connecting ability concerning oil product, water absorption, buoyancy and possible energy consumption has been identified.

\section{FEATURES OF THE SORPTION PROCESS}

The powder sorbent on the basis of iron powder or PO has a branched surface of particles with rather high specific surface. Monitoring has showed that the process of sorption is taking place in manifestation of the coagulation, gravitation and infiltration phenomena. Fine dispersed material is evenly dispersed or sprayed on a quiet surface of a water-oil layer. In addition to that, the smaller the powder, the more even turns out a covering. Further due to magnetic interaction and adhesion, suspension coagulates in large globules, clearing considerable part of a surface from the oil product film (up to 50\%). Accurately expressed clots (fig. 4) are formed from uniform layer of powder on the oil spot. They should be removed quickly enough as further under influence of the gravitational phenomena and infiltration of oil product in the pores of particles, the last fall to the bottom of a vessel (Fig. 5c). It occurs during 10-20 $\min$.
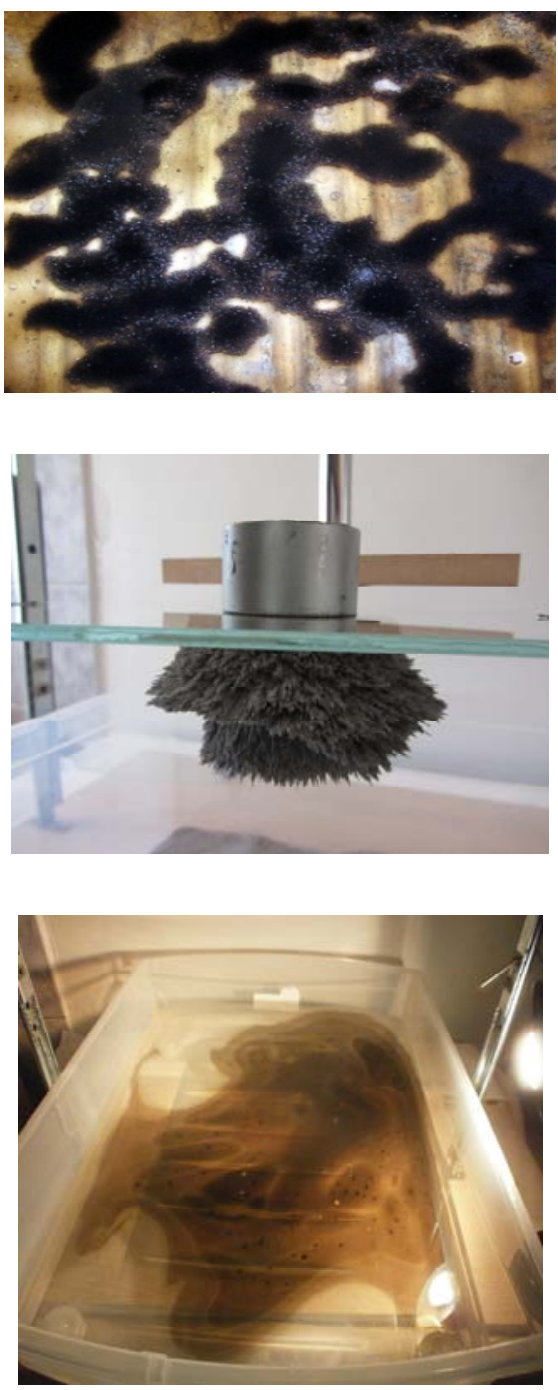

Fig. 4. Stages for performance of experiment a) coagulation of OPs: b) raising of SOPs, c) falling of OPs to the bottom of a vessel

The water oil film approaches the surface of firm particle of a powder sorbent under some acute angle $\theta$ (edge angle of wetting) characteristic for this couple liquid - solid body (Fig. 6). For improvement of process of sorption it is necessary to seek its reduction. It can be reached, for example, by means of preliminary processing of a powder sorbent in oil and its subsequent drying.

High importance on the process of sorption is rendered also by capillary phenomena in particles. Water oil liquid rises on capillaries of a porous particle until Ft gravity force operating on a liquid column in a capillary doesn't become equal to the module of surface tension forces (1)

$$
F n=\sigma 2 \pi r \cos \theta,
$$

where $\sigma-$ coefficient of a superficial tension of a film. 


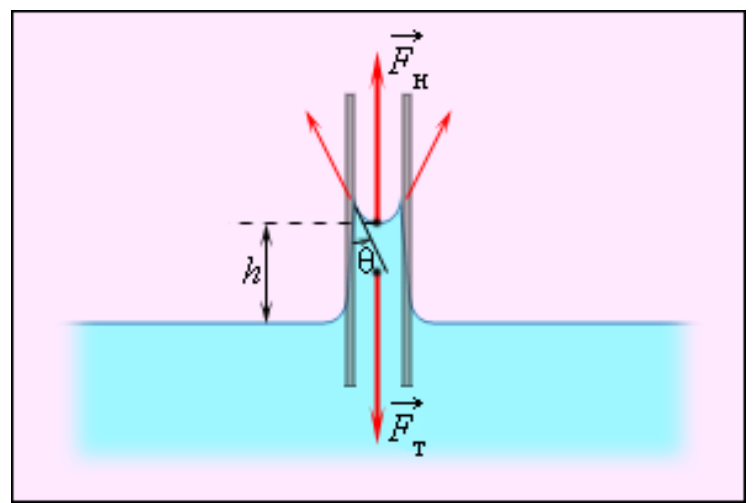

Fig. 5. The scheme of manifestation of capillary forces during sorption

Containment of collected oil product (SOPs) on a water oil surface is taking place not only due to forces of a superficial tension of the environment (in this case it is a water oil film), but also at the expense of air which is contained in the pores of particles of a sorbent.

The course of process to a large degree depends on dispersion of a powder sorbent, form of its particles, size of a specific surface, bulk weight, and also degree of dispersion and some other factors.

For removal of SOPs, force of a permanent magnet (or an electromagnet) is used, which necessary size depends from the gravity Fg and water oil film tension Fa (Fig. 6).

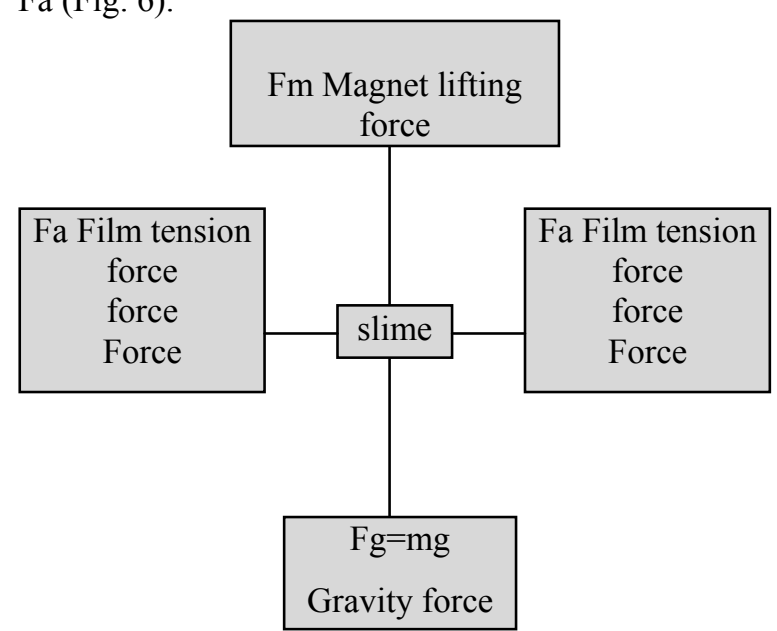

Fig. 6. The scheme of operation of forces in the course of magnetic

sorption.

Fg - Gravity force of slime (sorbent + oil product + water) depends on the weight and the specific weight of a sorbent, oil product and water.

For calculations of necessary lifting force it is possible to presume that the amount of water, contained in the sorbent pores, as up to $5-8 \%$, and oil absorption ability - up to $30 \%$ from the sorbent mass. The bulk weight of a sorbent on the basis of iron powders may be assumed as $0.8-2 \mathrm{~g} / \mathrm{cm}^{3}$, and sorbent layer thickness for removal of light oil products - not more than 1-3 mm. All this will allow determining the mass of a necessary sorbent.

At the moments of undulation of the water surface as a result of dispergating the water-oil emulsion, the content of water increases, which leads to increase in its apparent viscosity, and this, in its turn, increases power costs of sorption of such emulsion.

\section{CONCLUSIONS}

1. Use of ferromagnetic sorbents represents a perspective direction in the field of water purification from light oil products since it allows expanding the scope of the used powder sorbents, to use the highmechanized methods of collecting by means of magnetic and electromagnetic devices.

2. Process of magnetic sorption has some pronounced stages: coagulation, infiltration, separation of a collected product from the water-oil surface, transportation and warehousing.

\section{REFERENCES}

[1] Pat. 4784773, U.S., MCI C 02 F 1/40. Petroleum product absorption method and apparatus. Sandberg Fr.H.

[2] Orbell, JD, Dao, HV, Ngeh, LN, bigger, SW 2005, "Magnetic particle technology in environmental remediation and wildlife mental", Proceedings of the 9th Annual Environmental Postgraduate Conference, Hobart, Womack, 29 Nov- 2 December, 2005, pp. 1-7.

[3] Azizov A.A., Alosmanov R.M., Buniyat-zade I.A., Magerramov A.M., Mamedov G.G. Magnetic sorbent to remove thin oil films // Environmental Problems of Chemistry and Chemical Technology (in Russian - Магнитный сорбент для удаления тонких нефтяных пленок // Экологические проблемы химии и химической технологии). 2010, V. 53, No. 4, pp. 114-117.

[4] Shishkins, A., Mironovs, V., Lapkovskis, V., Treijs, J., and Korjakins, A. "Ferromagnetic Sorbents for collection and utilization of oil products," in Baltmattrib, Riga, Latvia, 2013, pp. 25-26.

[5] Mironovs, V., Lapkovskis, V., Zemčenkovs, V. Sorbent for collection of oil products (in Latvian - Sorbents naftas produktu savākšanai). LR patent LV 13927 B 20.08.2009, Int. Cl. B01J20/02.

[6] Mironovs, V., Belovs, V., Zemčenkovs, V. Equipment for collection of spilled oil products (in Latvian - Iekārta izlietu naftas produktu savākšanai). LR patent LV 13911 B 20.08.2009, Int. Cl E02B15/04.

[7] Shishkins, A., Mironovs V., Lapkovskis, V., Treijs, J., and Korjakins, A. "Ferromagnetic Sorbents for collection and utilization of oil products," in Baltmattrib, Riga, Latvia, 2013, pp. 25-26.

[8] Shishkins, A., Mironovs, V., Treijs, J., Baroniņš, J. Sorbent with ferromagnetic properties. LR Patent application LV 14822 B, 20.06.2014.

[9] Gorozhankina G.I., Pinchukova L.I. Sorbents for oil collection: comparative characteristics and special features of application. Pipeline Transportation of Oil (in Russian ). 2000. No. 4, pp. 12-17. 